\title{
Sistem pemantauan dan pengisian cairan pada mesin hemodialisa berbasis IoT dengan protokol MQTT
}

\author{
Yanda Aprinaldi ${ }^{1}$, Dede Irawan Saputra ${ }^{2 *}$ \\ ${ }^{1,2}$ Program Studi Teknik Elektro, Fakultas Teknik, Universitas Jenderal Achmad Yani \\ Jl. Terusan Jenderal Sudirman PO BOX 148, Kota Cimahi, Jawa Barat, Indonesia \\ ${ }^{1}$ yandaaprinaldy@gmail.com, ${ }^{2 *}$ dedeirawan.saputra@lecture.unjani.ac.id
}

\begin{abstract}
ABSTRAK
Masalah yang sering terjadi saat melakukan cuci darah adalah habisnya cairan acid dan bicarbonate saat proses cuci darah sedang berlangsung yang mengakibatkan efek samping pada pasien. Internet of Things (IoT) merupakan metode komunikasi sederhana yang dapat menghubungkan semua objek fisik di kehidupan seharihari melalui internet. Pada penelitian ini dibuat prototype berbasis IoT yang mampu memonitor dan mengisi ulang cairan acid dan bicarbonate dan dapat mengisi ulang cairan sebelum kosong. Sistem dibuat menggunakan sensor ultrasonic dan aliran untuk pendeteksian cairan. Pengiriman data pada sistem ini dilakukan menggunakan protokol Message Queuing Telemetry Transport (MQTT). Hasil pengujian menunjukkan sistem mampu berjalan dengan baik dengan tingkat error data sensor ultrasonik yang sudah terkalibrasi sebesar $0,105 \mathrm{~cm}$ dan error sensor flowmeter sebesar $0,11 \mathrm{~L} / \mathrm{m}$. Hasil pembacaan pada serial monitor memiliki hasil yang sama dengan pembacaan yang ditampilkan interface. Data yang dikirimkan mencapai kesesuaian $100 \%$ dikarenakan pada sistem monitor dan pengisian ini dilakukan menggunakan protokol MQTT yang terdapat publish, subscribe, dan broker.
\end{abstract}

Kata kunci: pemantauan, pengisian, hemodialisa, IoT, MQTT

\section{ABSTRACT}

The problem that often occurs when doing dialysis is the depletion of acid and bicarbonate fluids during the dialysis process which results in side effects in patients. Internet of things (IoT) is a simple communication method that can connect all physical objects in everyday life via the internet. In this study, an IoT-based prototype was created which was able to monitor and refill acid and bicarbonate fluids and be able to refill the liquid before it was empty. The system is made using ultrasonic and flow sensors for liquid detection. Data transmission in this system is carried out using the Message Queuing Telemetry Transport (MQTT) protocol. The test results show the system is able to run well with a calibrated ultrasonic sensor data error rate of 0,05\% and a flowmeter sensor error of $0,11 \%$. The reading on the serial monitor has the same result as the reading displayed on the interface. The data sent reaches $100 \%$ conformity because the monitoring and filling system is carried out using the MQTT protocol which contains publish, subscribe, and broker.

Keywords: monitoring, refilling, hemodialisys, IoT, MQTT

\section{PENDAHULUAN}

Proses cuci darah di rumah sakit dilakukan menggunakan sebuah mesin hemodialisa. Kebanyakan pada mesin tersebut tidak terdapat indikator peringatan berupa alarm atau perhitungan aliran cairan acid dan bicarbonat. Kehabisan cairan ini menjadi salah satu faktor yang harus diperhatikan. Dengan demikian, diperlukan sebuah sistem yang mampu mengamati dan juga mengisi cairan secara otomatis sebelum terjadi kekosongan pada galon acid dan bicarbonate.

Beberapa sistem telah dirancang untuk mengatasi permasalahan tersebut. Pada penelitian sebelumnya, pengamatan cairan ditampilkan pada LCD 16x2 yang dapat menampilkan data jarak cairan dengan satuan centimeter $(\mathrm{cm})$ kemudian saat cairan habis alarm akan berbunyi [1]. Kelemahan dari sistem ini adalah tidak bisa mengisi ulang cairan secara otomatis. Oleh karena itu, perawat harus mengganti cairan tersebut secara manual. Salah satu solusi alternatif yang dapat dilakukan yaitu dengan menerapkan sistem pengamatan dan juga refillable (isi ulang) cairan secara otomatis [2]. 
Sistem pengamatan dan refillable dapat direalisasikan dengan konsep machine to machine (M2M) dengan memanfaatkan Internet of Things (IoT) [3], [4].

Dalam sistem IoT, pemilihan protokol yang baik akan menentukan performansi dari sistem. Beberapa protokol yang mendukung realisasi IoT diantaranya Hypertext Transfer Protocol (HTTP) [5], [6] dan Message Queuing Telemetry Transport (MQTT) [7]. Protokol yang sering digunakan untuk sistem berbasis IoT adalah protokol MQTT [8]. Protokol MQTT dapat diaplikasian pada perangkat kontroler dan dapat diprogram mengunakan perangkat lunak dengan menggunakan konsep PubSubClient. Protokol MQTT memiliki ukuran paket data dengan low overhead yang kecil sehingga berefek pada konsumsi data yang cukup kecil [9], [10].

Penelitian ini bertujuan untuk merancang prototype sistem yang dapat mengamati dan mengisi cairan acid dan bicarbonate pada mesin hemodialisa secara otomatis dengan konsep IoT. Prototype ini terdiri dari beberapa hardware dan software dan dirancang dengan menggunakan protokol MQTT. Sistem ini terdiri dari modul WiFi ESP8266 yang digunakan untuk terhubung langsung dengan WiFi dan menjadi kontroler. Sistem juga akan mengolah data yang diterima oleh sensor ultrasonik HCSR04 yang digunakan untuk membaca jarak atau nilai batas atas dan batas bawah cairan. Kemudian sistem akan menampilkan data debit air yang diperoleh oleh sensor waterflow. Level cairan acid, status pompa, dan debit cairan merupakan data yang akan ditampilkan pada sebuah interface dengan memanfaatkan platform IoT geeknesia.com. Dengan adanya tambahan pada sistem ini diharapkan dapat di integrasikan pada sistem yang sebenarnya dan mampu meminimalisir efek buruk yang terjadi saat proses cuci darah saat terjadi kehabisan pada cairan acid dan bicarbonate.

\section{METODE PENELITIAN}

\subsection{Diagram Blok Sistem}

Metode yang digunakan dalam penelitian ini adalah rancang bangun dalam bentuk prototype. Gambar 1 merupakan blok diagram sistem yang terdiri dari sensor, NodeMCU, dan juga pompa. Proses pengiriman data dirancang menggunakan protokol MQTT. Sensor ultrasonik, flowmeter, dan NodeMCU yang bertugas sebagai publisher akan mengirimkan data jarak dan data debit cairan yang kemudian diteruskan pada platform IoT geeknesia.com. Platform ini akan bertugas sebagai broker. Setelah data diterima oleh broker, kemudian data akan diteruskan kepada subscriber dalam hal ini adalah tampilan pada laptop atau handphone.

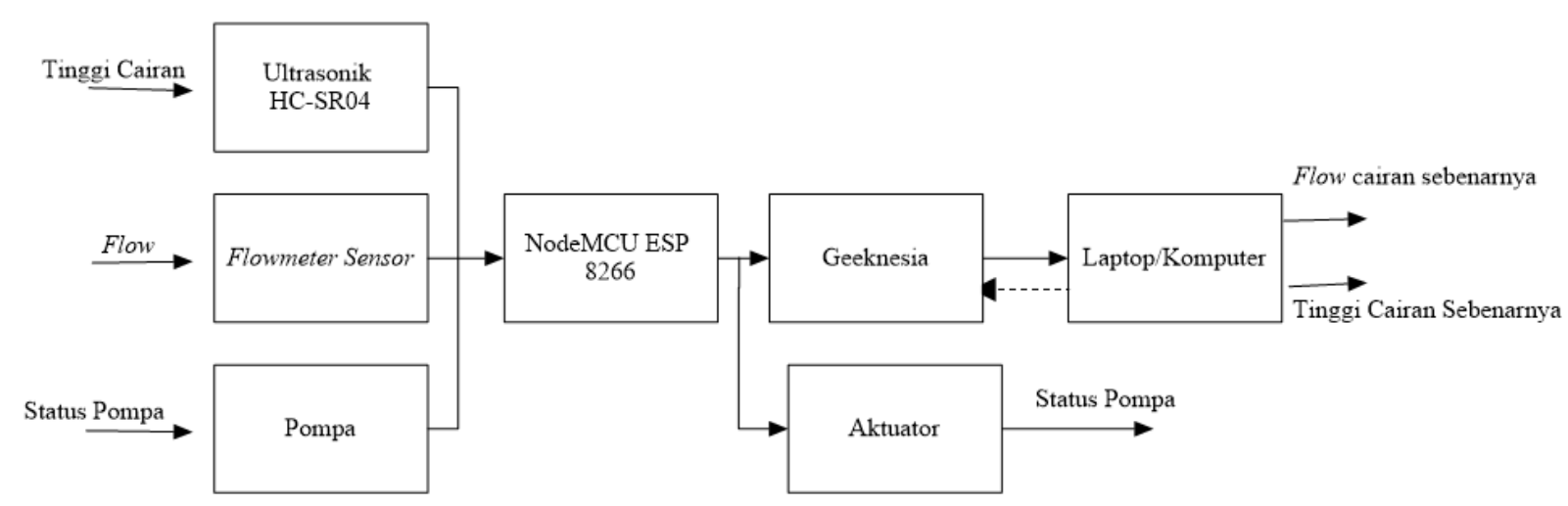

Gambar 1. Diagram blok sistem

\subsection{Arsitektur Sistem}

Gambar 2 menujukkan arsitektur IoT pada sistem yang dirancang. Sensor ultrasonik dan flowmeter yang bertugas sebagai publisher akan membaca jarak cairan $60 \%$ dan debit cairan 5 liter dengan topic "distance" dan "flowmeter". Setelah data dibaca kemudian dikirimkan menuju kontroler yaitu NodeMCU. Selanjutnya, data akan dikirimkan melalui broker dengan modul komunikasi ESP8266.

MQTT broker bertugas sebagai penghubung transaksi data antara publisher dan subscriber. Ketika publisher mengirimkan data sensor jarak 60 dan flowmeter 5 liter dengan topic "distance" dan "flowmeter", maka bisa dipastikan subscriber akan menerima data sensor ultrasonik dan flowmeter. 
MQTT subscriber blok ini bertugas untuk melakukan subscribe pada topic "distance". "flowmeter". Setelah mendapatkan data berupa nilai sensor ultrasonik 60\% dan flowmeter 5 liter dari publisher, data tersebut bisa dijadikan sistem monitor yang akan tampil pada interface, laptop, komputer, ataupun handphone.

Topic pada protokol MQTT bersifat wajib. Pada setiap transaksi, data antara publisher dan subscriber harus memiliki topic yang akan dikirimkan. Topic ini dikirimkan oleh publisher yaitu sensor ultrasonik dan sensor flowmeter, kemudian diteruskan pada broker berupa nilai dan diteruskan kepada client yaitu subscriber agae data ini dapat ditampilkan pada interface.

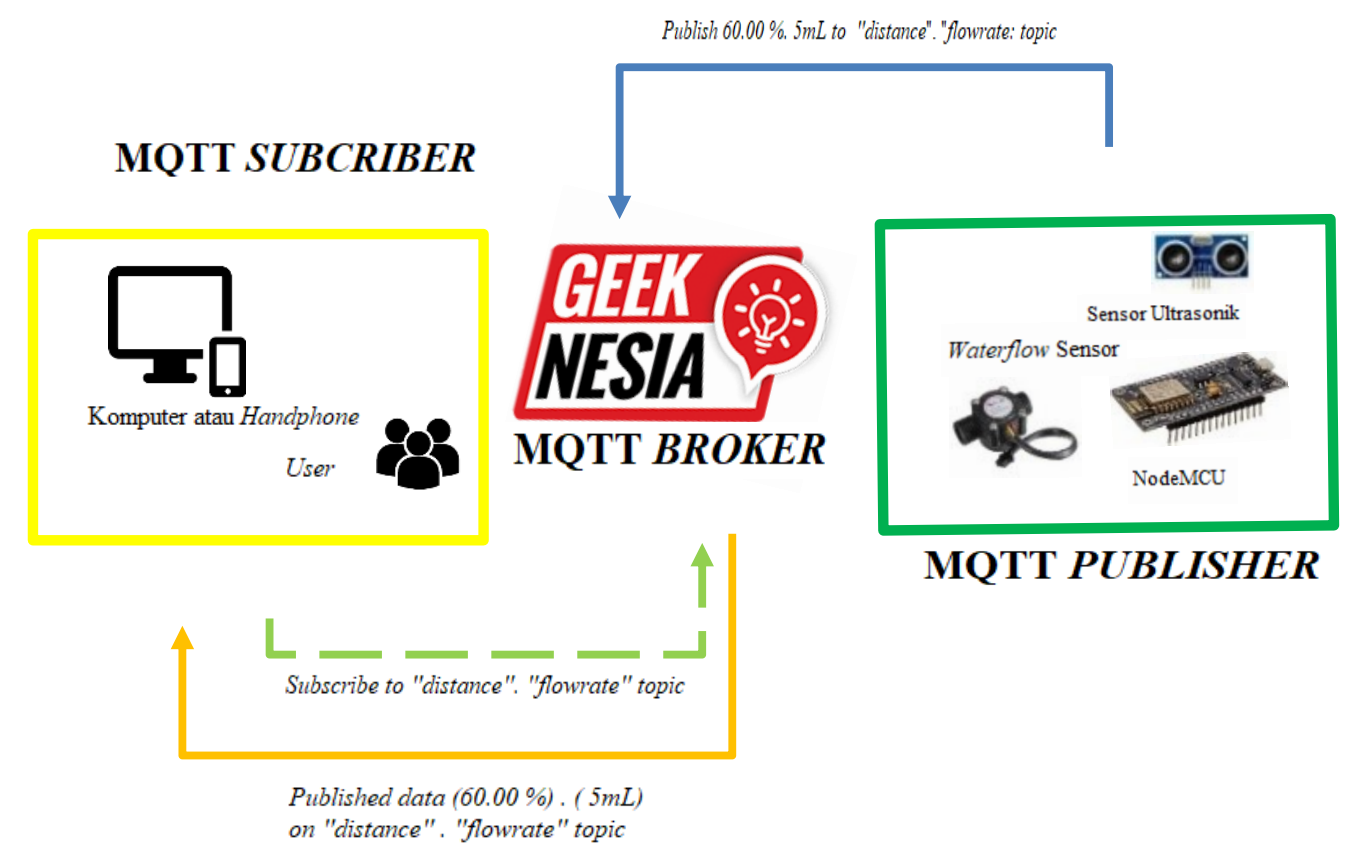

\section{Gambar 2. Arsitektur sistem}

\subsection{Komponen Sistem}

Rangkaian sistem ini memiliki beberapa hardware yang terdiri dari NodeMCU ESP8266, sensor ultrasonik HC-SR04, relai 2 channel, dan sensor flowmeter. Setelah rangkaian sistem dibuat, kemudian masing-masing pin dikonfigurasikan seperti yang ditunjukan pada Gambar 3.

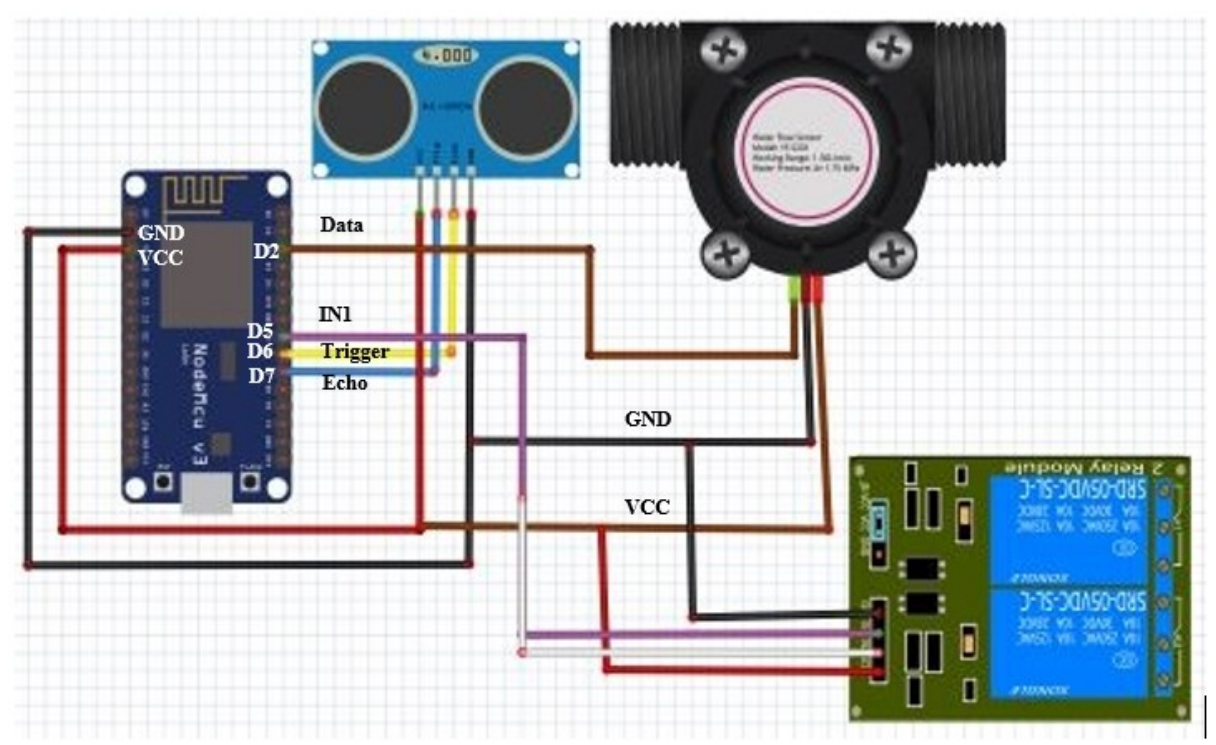

Gambar 3. Skematik sistem 


\subsection{Integrasi Protokol MQTT}

MQTTBox merupakan aplikasi client untuk protokol MQTT dan merupakan salah satu aplikasi yang dapat digunakan untuk implementasi client MQTT. Pada langkah ini, dibuat fitur feedback dari device ke cloud. Langkah pertama adalah melakukan instalasi MQTTBox pada browser chrome dan melakukan konfigurasi seperti ditunjukkan Gambar 4.

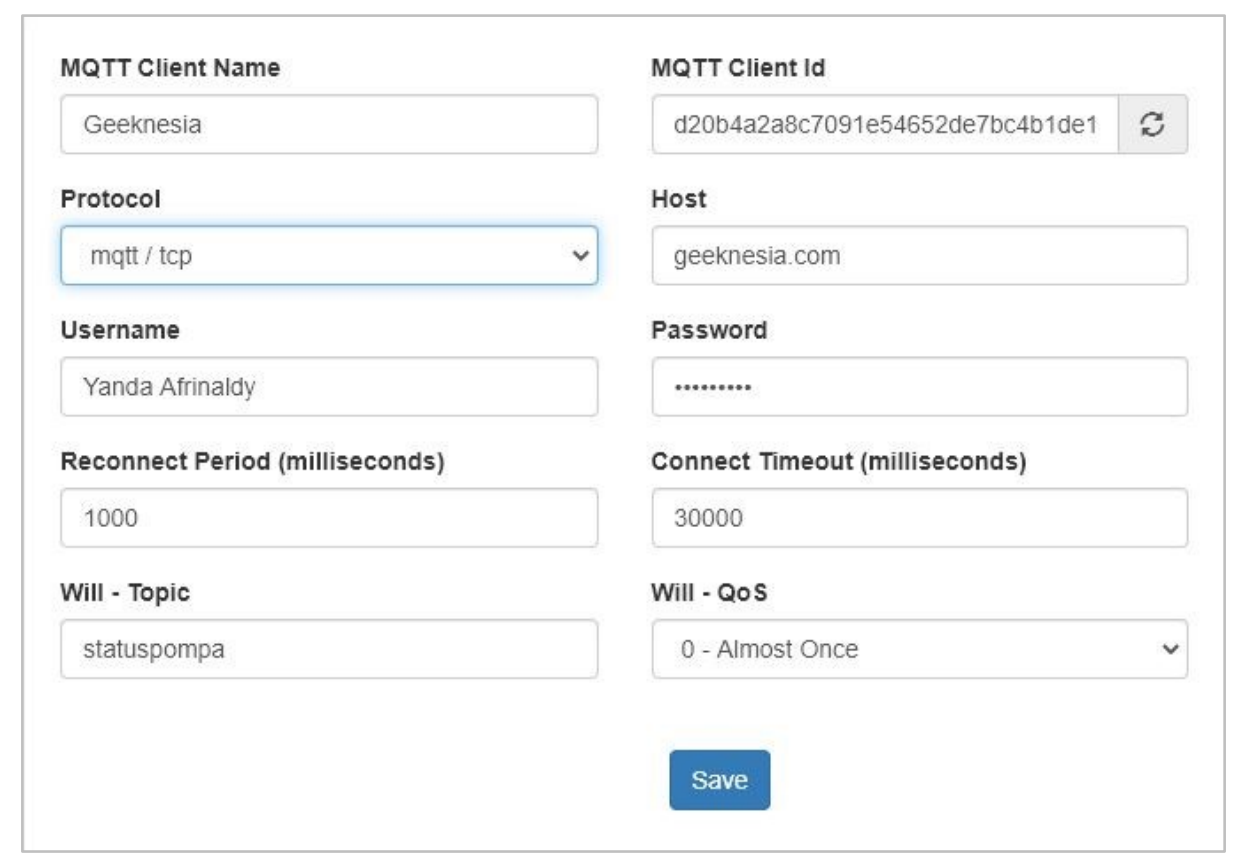

Gambar 4. Konfigurasi broker MQTT

MQTT client name diisi dengan broker yang digunakan yaitu geeknesia.com. Jika pada prototype menggunakan MQTT sebagai protokol, maka kolom protokol dimasukan MQTT/TCP. Kemudian mengisi username dan password sesuai dengan yang dimasukan pada coding yang telah dibuat. Pada MQTT client, isi data dengan data api key yang diterima pada saat membuat gateway di geeknesia.com. Setelah mengisi kolom sesuai dengan Gambar 4, maka tekan tombol save untuk menyimpan MQTT client yang telah dibuat. Kemudian hubungkan protoype dengan MQTTBox dan MQTT client akan terhubung seperti yang ditunjukan pada Gambar 5.

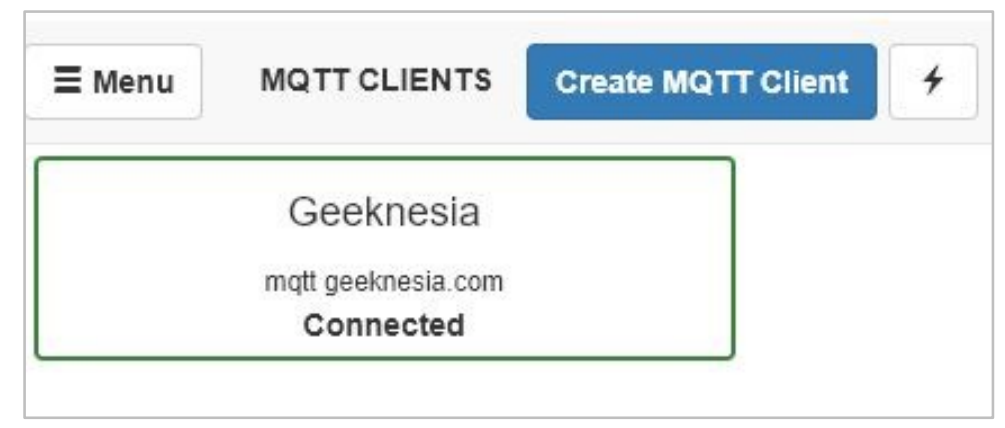

Gambar 5. Tampilan koneksi terhubung pada sistem

\section{HASIL DAN PEMBAHASAN}

Implementasisistem dilakukan sesuai dengan diagram skematik yang dijelaskan di bagian metode penelitian. Adapun hasil implementasi dari sistem hardware dapat dilihat pada Gambar 6. Setelah dilakukan integrasi sensor, kontroler, dan pompa yang akan digunakan untuk isi ulang cairan acid dan bicarbonate, langkah selanjutnya adalah pengujian sistem sensor dan pengiriman data menggunakan protokol MQTT. 


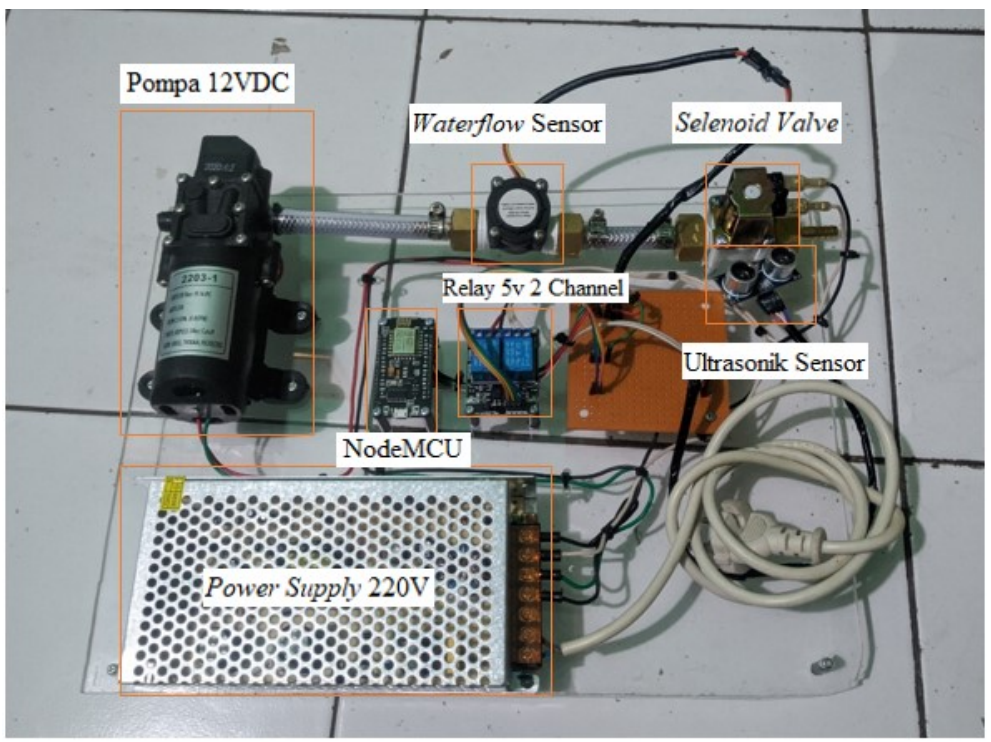

Gambar 6. Realisasi sistem

\subsection{Pengujian Sistem Sensor}

Pengujian ini dilakukan untuk mengetahui tingkat akurasi dari sensor ultrasonik dan flowmeter yang digunakan pada sistem. Pengujian dilakukan dengan cara membandingkan data pengukuran sensor dengan alat ukur sebenarnya. Kemudian, dihitung selisih (error) yang dihasilkan antara data sensor dengan alat ukur. Adapun hasil pengujian sistem sensor ditampilkan pada Tabel 1 dan Tabel 2.

Tabel 1. Pengujian sensor ultrasonik

\begin{tabular}{|c|c|c|c|}
\hline No & Sensor ultrasonik (cm) & Meteran manual (cm) & Error (cm) \\
\hline 1 & 10,01 & 10 & 0,01 \\
\hline 2 & 50 & 50 & 0 \\
\hline 3 & 100 & 100 & 0 \\
\hline 4 & 120,01 & 120 & 0,01 \\
\hline 5 & 150,01 & 150 & 0,01 \\
\hline 6 & 200 & 200 & 0 \\
\hline 7 & 225,02 & 225 & 0,02 \\
\hline 8 & 250 & 250 & 0 \\
\hline 9 & 300 & 300 & 0 \\
\hline 10 & 325,01 & 325 & 0,01 \\
\hline \multicolumn{2}{|r|}{ Error rata-rata } \\
\hline
\end{tabular}

Tabel 2. Pengujian sensor flowmeter

\begin{tabular}{|c|c|c|c|}
\hline No & Q ref (L/Min) & Q flowmeter (L/Min) & Error (L/Min) \\
\hline 1 & 9,7 & 9,5 & 0,2 \\
\hline 2 & 9,8 & 9,7 & 0,1 \\
\hline 3 & 9,8 & 9,5 & 0,3 \\
\hline 4 & 9,7 & 9,7 & 0 \\
\hline 5 & 9,9 & 9,8 & 0,1 \\
\hline 6 & 9,8 & 9,8 & 0 \\
\hline 7 & 9,7 & 9,5 & 0,2 \\
\hline 8 & 9,9 & 9,8 & 0,1 \\
\hline 9 & 9,8 & 9,7 & 0,1 \\
\hline 10 & 9,8 & 9,8 & 0 \\
\hline \multicolumn{3}{|c|}{ Error rata-rata } \\
\hline
\end{tabular}

Berdasarkan hasil pengukuran, nilai perbandingan antara pengukuran jarak menggunakan sensor ultrasonik dengan meteran manual menunjukan nilai yang sama pada beberapa pengukuran dan 
terdapat perbedaan kecil pada di beberapa pengukuran dengan kesalahan pengukuran sebesar 0,105 $\mathrm{cm}$. Nilai perbandingan antara pengukuran debit menggunakan flowmeter dengan nilai hasil pemompaan menunjukan nilai yang berbeda dengan selisih yang bervariasi namun tidak terlalu besar yaitu memiliki kesalahan rata-rata pengukuran sebesar $0,11 \mathrm{~L} /$ menit.

\subsection{Pengujian Protokol MQTT}

Gambar 7 menampilkan interface yang sudah dibuat. Pada gambar tersebut dapat dilihat publisher berupa sistem sensor flowmeter dan ultrasonik mengirimkan data pembacaan berupa level acid 30,06 \%, sensor flow dengan output flowmeter $9.218 \mathrm{~mL}$, dan status pompa running dengan debit terbaca $5 \mathrm{~L} / \mathrm{menit}$.

\begin{tabular}{|c|c|}
\hline $\begin{array}{l}\text { MONITOR CAIRAN ACID } \\
\text { HEMODIALISA }\end{array}$ & ADA MESIN \\
\hline Monitoring Sistem Cairan Acid & 凹 而 凹 \\
\hline \multicolumn{2}{|l|}{ Date : $5 / 9 / 202015.43 .34$} \\
\hline Attribute Name & Current Output \\
\hline Level Acid (\%) & 30.06 \\
\hline Pompa & Running \\
\hline Water Flow Rate (L/menit) & 5 \\
\hline Output Liquid Quantity (Mliter) & 9218 \\
\hline
\end{tabular}

Gambar 7. Tampilan antarmuka IoT

Data yang diterima oleh subscriber sesuai dengan topic yang dikirimkan oleh publisher seperti yang ditunjukan pada Gambar 8. Adapun pengujian pengiriman data dilakukan menggunakan MQTTBox dengan broker yaitu geeknesia.com dapat dilihat pada Gambar 9. Pada kolom topic to publish dimasukan "iot/data" data publish dan dapat disesuaikan dengan coding yang telah dibuat sebelumnya pada Arduino IDE.

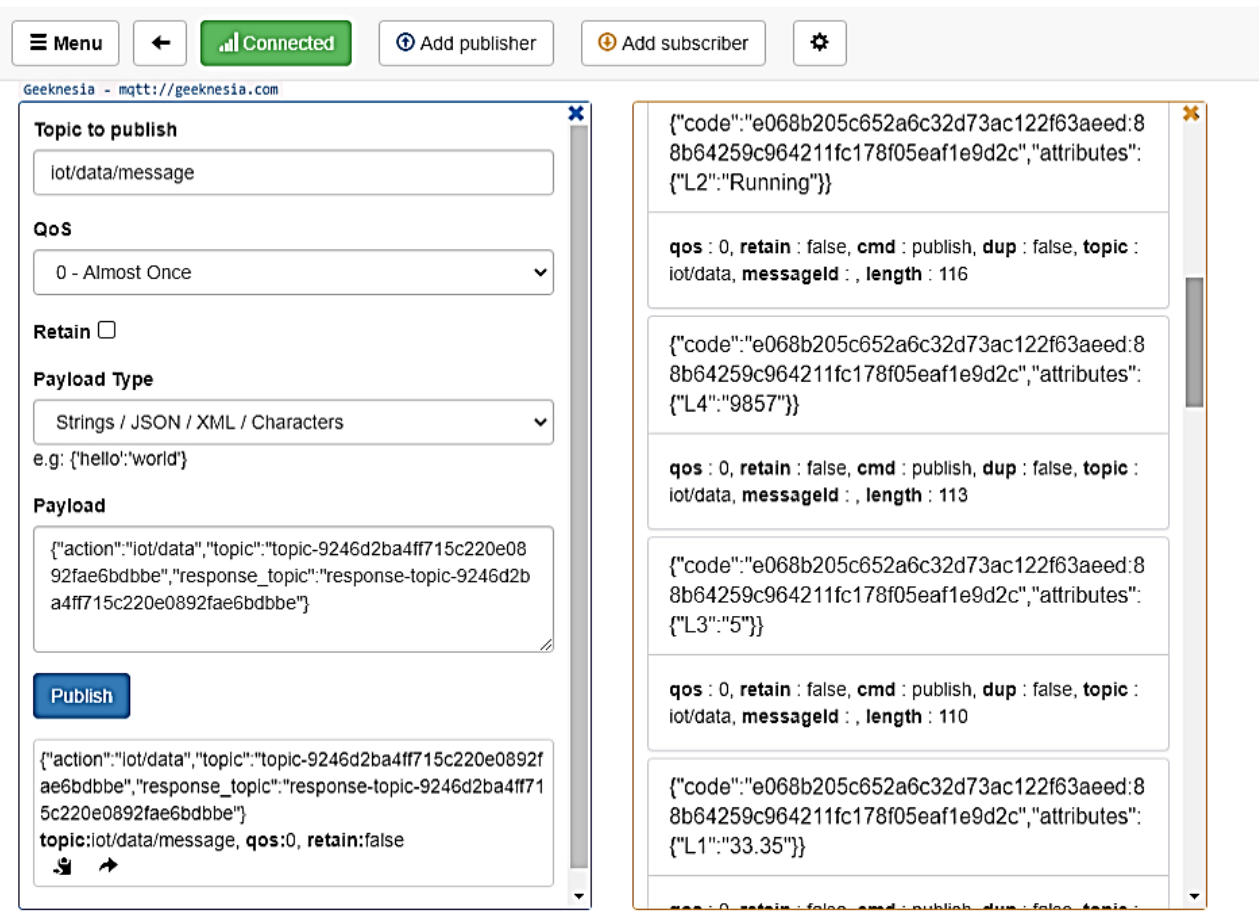

Gambar 8. Hasil publish dan subcribe 


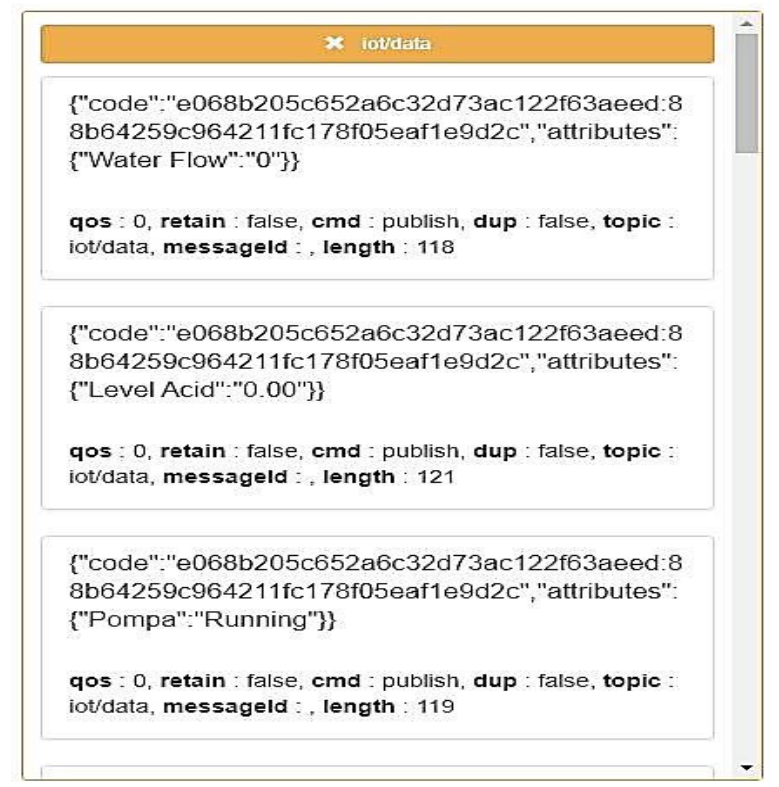

Gambar 9. Hasil pengujian MQTT client pada geeknesia.com

Setelah mengisi kolom topic to publish, selanjutnya menentukan Quality of Service (QoS) atau kualitas pelayanan yang akan digunakan untuk pengiriman data. Pada Gambar 9 menunjukkan QoS 0 yang berarti tingkat layanan ini menjamin pengiriman data dari publisher ke subscriber dengan upaya terbaik. Setelah mengisi kolom QoS selanjutnya mengisi payload type dengan memilih String/JSON/XML/Character. Format payload harus berupa JSON dengan 3 atribut utama yaitu action, topic, dan response. Topic akan mengirimkan data status pompa, level acid, water flowrate, dan output flow. Setelah mengisi payload type kemudian melakukan message dengan isi message "action"."iot/data"."topic"."topic-(sesuai dengan topic yang didapatkan pada geeknesia.com)"." response_topic"response-topic-(sesuaikan dengan topic yang didapatkan pada geeknesia.com). Setelah itu kemudian klik publish dan kemudian penerima atau subscribe akan menerima data sesuai dengan topic yang diminta. Dengan mekanisme ini, maka data yang publish akan diterima secara real time oleh subcriber.

\section{KESIMPULAN}

Sistem pemantauan dan pengisian cairan mesin hemodialisa berbasis IoT dengan protokol MQTT telah berhasil dirancang. Perangkat yang terhubung dengan internet melalui protokol MQTT yaitu sensor ultrasonik HC-SR04 dan sensor flowmeter. Berdasarkan hasil pengujian, sensor ini dapat bekerja sebagai publisher dengan rata-rata kesalahan pengukuran jarak sebesar $0,105 \mathrm{~cm}$ dan rata-rata kesalahan aliran cairan sebesar $0,11 \mathrm{~L} / \mathrm{m}$. Sistem mampu mengirimkan data dengan topic yang diinginkan dan mampu diterima dengan baik oleh platform geeknesia.com sebagai broker dan laptop sebagai subscriber dapat menerima topic yang dikirimkan oleh publisher. Dengan sistem ini, data dari sensor dapat ditampilkan pada user interface atau subscriber secara real time. Pada penelitian berikutnya diharapkan dapat mengembangkan arsiektur IoT pada sistem pemantauan dan pengendalian cairan ini dengan membandingkan antar QoS dari protokol MQTT.

\section{REFERENSI}

[1] I. Jaya and M. Ilham, "Sistem Monitoring Supply Air Pada Aalat Hemodialisa Berbasis Arduino Uno ATmega 328," J. LITEK J. List. Telekomun. Elektron., vol. 16, no. 2, pp. 48-51, 2019.

[2] F. S. Fahmi and D. I. Saputra, "Pengontrolan Bukaan Valve Pada Sistem Vessel Separator Dengan Metode Logika Fuzzy Berbasis Node Nirkabel," in SENTER 2019: Seminar Nasional Teknik Elektro 2019, 2019, no. November 2019, pp. 135-149.

[3] R. Aburukba, "Role of Internet of Things in the Smart Grid Technology," J. Comput. Commun., vol. 3, no. May, pp. 229-233, 2015.

[4] D. I. Saputra, A. Rohmat, A. Najmurrokhman, and Z. Fakhri, "Implementation of Fuzzy Inference System Algorithm In Brooding System Simulator With The Concept of IoT And Wireless Nodes Implementation 
of Fuzzy Inference System Algorithm In Brooding System Simulator With The Concept Of Iot And Wireless Nodes," in ICIEVE 2019, 2020, pp. 1-6..

[5] W. Hlaing, S. Thepphaeng, V. Nontaboot, N. Tangsunantham, T. Sangsuwan, and C. Pira, "Implementation of WiFi-Based Single Phase Smart Meter For Internet of Things (IoT)," 2017 Int. Electr. Eng. Congr. iEECON 2017, no. March, pp. 8-10, 2017.

[6] N. Hidayati, "Prototype Smart Home Dengan Modul Nodemcu Esp8266 Berbasis Internet Of Things (IoT)," Tek. Inform. Univ. Islam Majapahit, 2018.

[7] W. Ma'ruf, D. I. Saputra, and S. Sambasri, "Perancangan Sistem Pengamatan dan Pengendalian Penggunaan Air Artesis beserta Informasi Biaya Berbasis Sensor Nirkabel dan IoT," vol. 13, no. 2, pp. 148-156, 2020.

[8] D. I. Saputra, G. M. Karmel, Y. B. Zainal, S. Teknik, E. Universitas, and J. Achmad, "Perancangan dan Implementasi Rapid Temperaturw Screening Contactless Dam Jumlah Oorang Berbasis IoT Dengan Protokol MQTT," JEEE, vol. 2, no. 1, pp. 20-30, 2020.

[9] V. Sarafov and J. Seeger, "Comparison of IoT Data Protocol Overhead," Semin. Futur. Internet SS2017, Dep. Informatics, Tech. Univ. Munich, no. March, pp. 7-14, 2018.

[10] R. K. Kodali and K. S. Mahesh, "A Low Cost Implementation of MQTT using ESP8266," in Proceedings of the 2016 2nd International Conference on Contemporary Computing and Informatics, IC3I 2016, 2016, pp. 404-408. 